\title{
Guest Editor's Foreword: \\ Proceedings of the 18th Biennial Symposium of the International Colour Vision Society. Held July 2005, Lyon, France
}

The International Colour Vision Society (ICVS) held its 18th biennial meeting in Lyon, France in July 2005. The ICVS, originally founded in 1967 as the International Research Group in Colour Vision Deficiencies and renamed in 1997, brings together vision scientists and clinicians with a common interest in color vision and color vision deficiencies. With significant technological advances that have permitted new and deeper questions about color vision to be addressed, the subject matter of recent meetings has expanded to include greater contributions from such areas as molecular genetics and evolution, retinal and cerebral imaging studies and computational modeling. The peer-reviewed papers in this volume span these newer and the more traditional topics of interest to the society, covering both applied and fundamental topics.

We are grateful to the contributors and the reviewers who made this issue possible. We thank the Editor-in-Chief for this second opportunity to publish our proceedings in Visual Neuroscience, and the staff for their patience and help during the review process. We also thank Cambridge Research Systems, the Institut Féderatif des Neurosciences de Lyon, the Pôle Rhône-Alpes de Sciences Cognitives, the University of Grenoble 2, Inserm, the Ville de
Lyon and Lyon Tourisme et Congrès for their generous support that made the symposium possible.

We invite your membership in ICVS (www.icvs.info) and your attendance at future symposia. For membership information, contact Dr. Neil Parry (neil.parry@manchester.ac.uk). Previous meetings of the society have been held in Sydney, Tübingen, Pau, Ghent, Göttingen, Cambridge (UK), and Seattle. The next Symposium will be held in Belém, Brazil.

Steven Buck University of Washington, Seattle, USA

Maureen Neitz Medical College of Wisconsin, Milwaukee, USA

Barry B. Lee State University of New York College of Optometry, New York, USA

Kenneth Knoblauch, Inserm, Bron, France 


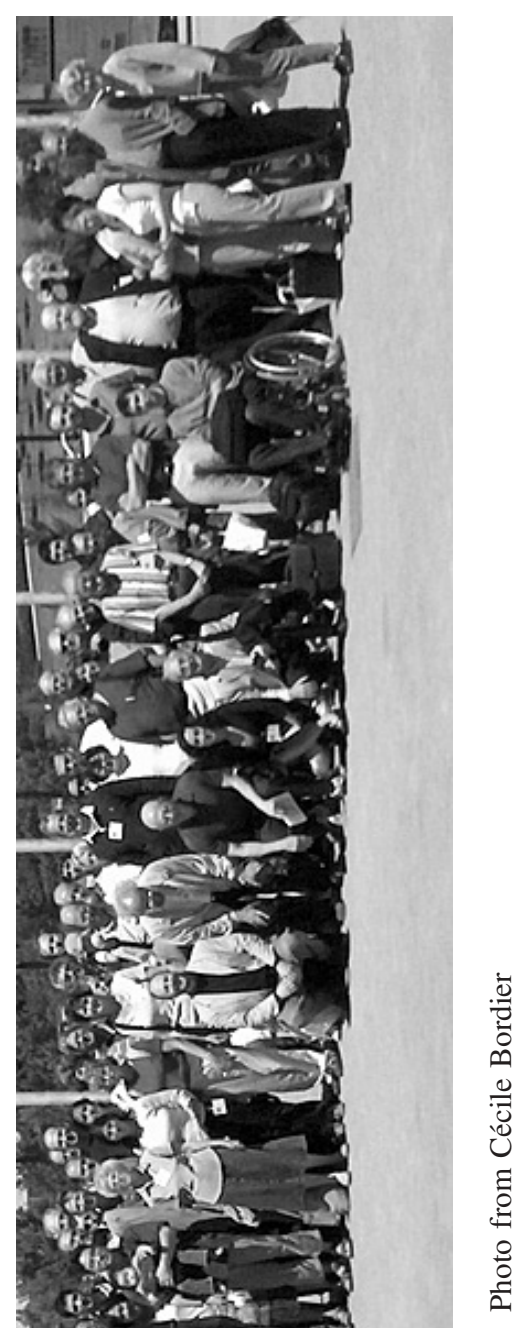

